\title{
Apresentação: Educação Superior em Contextos Emergentes
}

\author{
Maria Isabel da Cunha* \\ Marília Morosini** $^{* *}$ \\ Tânia Baibich ${ }^{* * *}$
}

O dossiê reúne artigos decorrentes de pesquisas que abordam políticas e práticas protagonizadas por universidades do Brasil e outros países para responder às demandas contemporâneas que estão a exigir mudanças epistemológicas, pedagógicas e culturais na vida acadêmica.

A proposta potencializa o diálogo de autores que desvelam realidades da academia e as novas fronteiras da universidade contemporânea, ainda pouco compreendidas em seus limites e possibilidades. Para tal, interpelam políticas e práticas que estão a ocorrer em contextos emergentes às novas realidades da educação superior nos diferentes países e na perspectiva da universidade latino-americana.

Os textos atendem ao interesse de uma população acadêmica em expansão, docentes, estudantes, técnicos e gestores, que deseja entender os rumos atuais da universidade, incluindo a compreensão conceitual sobre os contextos emergentes como processos de transição. São inerentes a um

[...] estado de mutação que se encontra em todas as partes e tem pontos de contato, de domínio e de diferenciação, mas como se trata de uma transição histórica de longo prazo, se apresenta muito complexo e congregador de forças que chegam de todos os lados e têm efeitos e causas desiguais entre o que está determinado

* Universidade Federal de Pelotas, Programa de Pós-graduação em Educação. Pelotas, Rio Grande do Sul, Brasil. E-mail: cunhami@uol.com.br. http://orcid.org/0000-0003-4129-7755.

** Pontifícia Universidade Católica do Rio Grande do Sul, Programa de Pós-graduação em Educação. Porto Alegre, Rio Grande do Sul, Brasil. E-mail: mariliamorosini@hotmail.com. http:// orcid.org/0000-0002-2433-5783.

*** Universidade Federal do Paraná, Programa de Pós-graduação em Educação. Curitiba, Paraná, Brasil. E-mail: tbaibich@gmail.com. https://orcid.org/0000-0001-8561-1713. 
e o que está surgindo (DIDRIKSSON, 2008, p. 5).

Nesse cenário, entende-se por contextos emergentes, na perspectiva da educação superior, construções observadas em sociedades contemporâneas que convivem em tensão com concepções pré-existentes, refletoras de tendências históricas (MOROSINI, 2014). São contextos que têm o ethos do desenvolvimento humano e social na globalização, em que há interação com outras formas de contextos. Estudos têm sido realizados para clarificar, identificar e compreender as tensões e estratégias que a educação superior aciona frente aos contextos emergentes (RIES, 2015).

As concepções de universidade tradicional e do século XXI enfrentam-se em novas fronteiras ainda sem limites e definições. Parte-se da premissa que o entendimento das fronteiras da universidade no contexto contemporâneo exige múltiplos olhares para sua configuração. Assume-se a dialeticidade das tendências tradicionais na medida em que elas alavancam a emergência do novo.

$\mathrm{O}$ dossiê resulta da parceria entre pesquisadores preocupados com a construção de novos conhecimentos que atentem aos múltiplos problemas que incidem na universidade enquanto reflexo da sociedade, sem deixar de lado a preocupação central com o desenvolvimento científico e tecnológico de cada realidade.

A perspectiva foi trazer elementos para a compreensão das estratégias que a universidade, comprometida com os problemas do local e voltada aos apelos da inserção internacional/global, aciona frente a dimensões caracterizadoras dos contextos emergentes. São epistemologias e metodologias, políticas e gestão, práticas pedagógicas e de formação, avaliação e ensino, todas elas dimensões que se desenvolvem no plano do local e que são "transversalizadas" pelos processos de internacionalização das universidades.

Os temas da educação superior sob a ótica dos organismos internacionais, da universidade "global" e o conhecimento social emergente, da geração do estudante e a equidade na educação superior, da construção da gestão participativa e o lugar do ensino como função prioritária da universidade são seguidos pela discussão sobre os sentidos da docência de qualidade. Nessa perspectiva estão colocados em diálogo com os enfoques abordados por intelectual da Argentina que explora as tendências da universidade, suas políticas e estratégias. Também incorpora uma importante contribuição do Canadá, a respeito das metodologias de pesquisa qualitativa no campo da educação.

A leitura dos artigos selecionados para esta publicação pretende esclarecer e dar respostas a questões que interpelam a educação superior levada 
a cabo em universidades contemporâneas colocadas em novas fronteiras de pensamento e atuação. O dossiê vai, certamente, contribuir com a produção no campo de conhecimento educacional e trazer a potencialidade necessária, na perspectiva teórica e dos problemas práticos, para compreender contextos emergentes em tensão com concepções pré-existentes, refletoras de tendências históricas da universidade.

Nesse entender, o dossiê tem como artigo inicial o Ensino superior na ótica dos organismos internacionais, escrito por Olgaíses Maués, da UFPA, que tem como objetivo a análise das posições de organismos internacionais relativas à reconfiguração do papel da educação superior na contemporaneidade, em função das exigências feitas pela sociedade do conhecimento, compreendido como imperioso para a formação do cidadão global para enfrentar os grandes desafios do mundo e as demandas da humanidade.

O segundo texto, escrito por Marcela Mollis, da Universidad de Buenos Aires (UBA), tem como foco Tendencias universitarias argentinas (20032015) e aborda o campo universitário durante os últimos 12 anos de continuidade de um partido político peronista, de 2003 a 2015. O artigo articula as dimensões da transformação do ensino superior em democracia, enfatizando as políticas de expansão, democratização e feminização nos últimos 12 anos à luz da universalização global do ensino superior.

$\mathrm{O}$ terceiro texto, Conhecimento Social Emergente e Conhecimento Glocal, escrito por Denise Leite e Elizeth Gonzaga dos Santos, da Unemat, tem como objetivo analisar o que está sendo posto como verdade para a universidade, desvelando outras instâncias, pouco conhecidas, como o são aquelas das ações com pertinência local/regional. O texto mostra saberes, percepções e ações invisíveis às avaliações, propondo que o conhecimento local-regional, o conhecimento social emergente, também pode ser internacionalizado, tornando-se conhecimento glocal, sendo local, regional e global ao mesmo tempo.

O quarto texto, Os desafios da construção da gestão participativa na universidade, escrito por Andreia do Rocio Caldas e Deise de Lima Picanço, da UFPR, busca delinear a trajetória na gestão do Setor de Educação da UFPR, no período de 2010 a 2014, buscando indicar os desafios da construção de bases mais participativas na gestão acadêmica. Procura deslindar os impasses presentes na cultura enraizada de uma instituição calcada nos moldes da estrutura legada pela ditadura militar e as potencialidades advindas dos novos processos democratização.

O quinto texto, Estudantes de Primeira Geração (P-Ger) na Educação Superior brasileira: analisando os dados da PNS - 2013, escrito por Marília Morosini (PUCRS) e Vera Felicetti (UniLaSalle), com olhar prospectivo, re- 
flete acerca do novo perfil estudantil na educação superior. Para tal, discute, inicialmente, com fundamento em pesquisa bibliográfica o conceito de estudante de $1 .^{\text {a }}$ geração (P-Ger) e suas características. Num segundo momento, são analisados, de forma inédita, dados sobre os P-Ger, em fonte oficial da Pesquisa Nacional da Saúde (PNS) do Instituto Brasileiro de Geografia e Estatística (IBGE), de 2013, e são levantadas considerações quanto à inclusão dos P-Ger na educação superior do país, destacando o processo de colaboração institucional para a minimização das tensões entre dominantes e dominados no campo científico.

$\mathrm{O}$ sexto texto, A formação docente na universidade e a ressignificação do senso comum, escrito por Maria Isabel da Cunha, da UFPel, insere-se no campo da formação para a docência da educação superior e procura avançar a discussão baseada em teorias do conhecimento que valorizam o senso comum e sua relação com o cotidiano. Aliando-se à corrente que valoriza o senso comum e as energias que circulam nos processos formativos, procura respostas teóricas que sustentem novas investigações.

O sétimo texto, Docência no ensino superior: interpelando os sentidos e desafios dos espaços institucionais de formação, escrito por Mara Regina Lemes de Sordi, da Unicamp, discute os conflitos vividos por docentes ingressantes em universidades públicas frente às narrativas sobre os sentidos de uma docência de qualidade em confronto com a precariedade das condições de apoio institucional, que recebem para dar concretude a um fazer pedagógico inovador e situado historicamente. Recorre-se à categoria da avaliação para fomentar processos de reflexão.

$\mathrm{O}$ oitavo texto, The role of critical qualitative research in educational contexts: A Canadian perspective, escrito por Susan Tilley, da Brocku University, Canadá, explora estudos sobre educação superior com foco no acesso, na evasão e na qualidade do trabalho desenvolvido. O texto examina pesquisas qualitativas, sua epistemologia e metodologias com o fito de melhor compreender essas questões.

A perspectiva dos autores é de que os textos possam contribuir com a comunidade acadêmica e interessados no campo da educação superior, problematizando contextos contemporâneos e emergentes. A condição do diálogo constitui-se num dispositivo potente para fazer avançar a área. 


\section{REFERÊNCIAS}

DIDRIKSSON, A. et al. Contexto Global y Regional de la Educación Superior en América Latina y el Caribe. In: UNESCO. La educación superior en el mercado. Configuraciones emergentes nuevos provedores. Venezuela: IESALC/UNESCO, 2008. Disponível em: http://200.6.99.248/ bru487cl/files/CAPITULO_01_Didriksson.pdf.

MOROSINI, M. Qualidade da educação superior e contextos emergentes. Avaliação (Campinas) [online]. 2014, vol.19, n.2, pp.385-405.

RIES - Rede Sul Brasileira de Investigadores da Educação Superior. Educação Superior em Contextos emergentes. PRONEX - Programa Núcleo de Excelência em Ciência Tecnologia e Inovação. CNPq/FAPERGS. Porto Alegre: CNPq/FAPERGS, 2015. 